\title{
Changes in the internal structure of bronze and iron over time at ambient temperature
}

\author{
Jaroslav Fiala ${ }^{1}$, Jaroslav Pavelka ${ }^{2}$, Jiří Kř̌́ž², Martin Hložek ${ }^{3}$, Pavel Hušt’ák ${ }^{4}$ \\ ${ }^{1}$ New Technologies - Research Centre in Westbohemian Region, Plzen, Czech Republic \\ ${ }^{2}$ University of West Bohemia, Plzen, Czech Republic \\ ${ }^{3}$ Centre for Archaeological Research of Social, Structures from Primeval to Middle Ages, Masaryk University, Brno, Czech Republic \\ ${ }^{4}$ Pueblo - archeologická společnost, o.p.s. Pueblo (Archaeology Company Pueblo), Podjavorinské 1601/8, Praha, Czech Republic
}

\section{Email address:}

japetos@kar.zcu.cz, Japetos@seznam.cz (J. Pavelka)

\section{To cite this article:}

Jaroslav Fiala, Jaroslav Pavelka, Jiří Kříž, Martin Hložek, Pavel Hušták. Changes in Internal Structure of Bronze and Iron over Time at Ambient Temperature. Advances in Materials, Vol. 2, No. 4, 2013, pp. 53-58. doi: 10.11648/j.am.20130204.12

\begin{abstract}
This study analyzes changes in the inner structure of metals (bronze and iron) resulting from aging and creeping processes. A remarkable disproportion was noticed during hardness analyses of original metal objects from archaeological finds and replicas likely made in the same way as the originals. The mechanism of such long-term changes at ambient temperature remain unknown. We examined the azimuthal (lateral) diffraction line profile, which includes the size, number and shape of individual diffraction spots comprising a discontinuous diffraction line. By x-ray analysis, all of the original bronze and iron artifacts were proven coarse-grained; coherent areas (mosaic blocks) were larger than $10 \mu \mathrm{m}$. The original structure of objects produced by the forging of sponge iron must have been much more fine-grained. The measurements revealed that the mechanism responsible for the change in the structure of forged artifacts over time is spontaneous recrystallization. We found that spontaneous recrystallization occurs much more quickly than usually expected at ambient temperature. We derived formulas explaining how the mechanism of relaxation changes on cooling from high to ambient temperature. Some low-energy mechanisms are blocked at elevated temperatures but released at ambient temperature. The activation energy of such mechanisms is much lower than the activation energy of relaxation processes at elevated temperatures. Our findings can be usefully exploited when monitoring processes that degrade the structure of a material in the course of its service.
\end{abstract}

Keywords: X-Ray Diffraction (XRD), Iron, Recrystallization

\section{Introduction}

Aging and creep processes (Mohan \& Marschall, 1998; Guoa et al., 2003; Castellero et al., 2008) are slow at ambient temperature, so they can be only observed in very old objects. Metal aging has been studied so far only under high temperatures (for example, Angelini et al., 2004); there are no studies of aging at common environmental temperatures over a long period.

Ancient metals represent suitable materials for the testing of aging processes because the changes in metal structures over the course of many centuries are significant and easily measurable. The internal structure of a metal is not usually observed in standard archaeological practice; only hardness is sometimes determined. Through time, recrystallization occurs, a spontaneous change of solid structure (Fiala \& Kocich 2006). Recrystallization lowers the internal energy of the solid phase by removing and reconfiguring structural defects and eliminates work hardening that occurs during forging (Fiala \& Kocich 2006). Therefore, we suppose that, in the long period of time following the processing of metal artifacts (bronze or steel), the hardness induced by hammering partially relaxed, and the artifacts softened. Recrystallization processes are accelerated by increases in temperature; therefore, they are usually studied at elevated temperatures. At ambient temperature, the effects of recrystallization become evident only after hundreds of years, and this is the subject of our study.

Changes in the structure are not visible when observed with an optical microscope (where the observed size of crystals is $0.1-10 \mu \mathrm{m}$ ). On the other hand, the magnification obtained with transmission electron microscopy is too high, and statistically significant information cannot be obtained 
easily for objects larger than $10 \mu \mathrm{m}$. Moreover, the process of preparing a sample for a transmission electron microscope is problematic, requiring very thin translucent foils that may change the crystal structure of the original material considerably (Fiala et al. 2002). Scanning electron microscopy works at suitable magnification (examining details larger than $10 \mu \mathrm{m}$ ), but its structural contrast is low. This technique is more suitable for surface microgeometry or microanalysis of elemental composition than for inner structure analysis (Fiala et al. 2002). X-ray diffraction is the most efficient technique for observing recrystallization (Fiala \& Kocich 2006). After incident X-rays on a polycrystalline material are diffracted, a system of conical surfaces is created whose common axis is the primary (incident) beam. This diffracted radiation can be recorded, and we thus obtain a diffraction pattern (Sun et al., 1999, Fiala et al. 2002). A diffraction pattern is composed of a system of lines (diffractions) that have a certain width and distribution. We can obtain information about structural anisotropy (texture) and details (elements larger than $10 \mu \mathrm{m}$, i.e., mesostructure) (Fiala et al. 2002) of the inner architecture of the material from analysis of diffraction patterns (Sun et al. 1999, Duclaux et al. 2003). Similar diffraction methods and materials were used by Bourdoiseau et al. (2008); however, their study examined corrosion layers in nanocrystalline and Fe(III)-containing mackinawite, not changes of Fe crystals inside the metal object.

X-ray diffraction has been used previously for the analysis of the inner structure of ancient metal. The famous copper axe of the Iceman has been the subject of this type of analysis. The axe was found on ice with a mummy dated to approximately 5200 BP (Artioli, et al. 2003, Artioli \& Dugnani 2004). It seems that there was no obvious recrystallization on the forged blade, although the axe must have been deformed in various places during the manufacturing process. The degree of recrystallization at a given temperature and time highly depends on the degree and manner of material deformation. If the deformation lies beyond a critical level, the corresponding increase of the material's thermodynamic potential does not sufficiently drive the ensuing recrystallization. The recrystallization cannot take place also in case that the strain is too large, making the activation energy of the recrystallization process much too high.

The aim of this study is to determine the change in metal structures over the course of centuries. We chose a bronze sword, which carries the tracks of a used weapon, and an iron object to test our hypothesis of recrystallization for aging and creep processes at ambient temperature.

\section{Experimental Procedure}

The examined bronze material had to be selectively chosen. Cast bronze weapons were hardened by forging, which is evident from the different hardnesses found outside and inside the dagger blades (Grömer \& Mödlinger
2005, Mödlinger 2005, Shalev 2004). Cold working is usually observed in the studies (McConchie 2004, Buchwald 2005). Forging causes changes in the inner structure of metals (Fiala \& Snyder 1999, Fiala \& Kolega 2005). We also examined changes in the structures of ancient, medieval and modern iron and steel objects. The forging of sponge iron was the only technology for production of iron articles in Europe until the late 14th century (Read 1934, White 1940, Temple 1989, Degarmo et al. 2003). The relevant subjects were indubitably forged well, and if they have not gone through secondary heating (such as in a wildfire), their structure was originally fine-grained. If accidental secondary heating has not happened, we can understand this structure as proof that structural changes over time also occur in other products processed by a blacksmith.

Original bronze swords were used for the analysis (Albrechtice nad Vltavou, Czech Republic, younger Bronze Age, and the entire sword, Hallstatt period, Jarošovice, Czech Rep.)*. The process of hardening from some of the available techniques can be presumed, especially on the edges. Therefore, we used the edge area for our examinations. Recent replicas were made by a blacksmith (sword-cutter) who has been working with bronze for ten years (Bohuslav Ježdík, Chrančovice 49, Líšt’any, 33035 Czech Rep.). Ancient iron artifacts are not often preserved in a suitable state, so a more readily available Medieval Age material was used for verification (9 arrowheads for crossbow arrows and 2 axes. Site Kladruby, Czech Rep.). Artifacts from the Roman period were used as well (site Mušov - Burgstall, Czech Rep.).

The double-edged La Tène iron sword (inventory no. A 483324) has been chosen for precise analysis. The 90-cm-long sword was found in grave no. 557, excavated in the year 2008 in locality Praha (Prague)-Jiviny (Czech Republic). This object remained underground in a scabbard made of metal plate without any contact with the aboveground environment for approximately 2300 years (Hušták 2009). The weapon has been buried along with its deceased owner in a grave $1.5 \mathrm{~m}$ deep and remained intact until the analysis. The sword was forged and most likely not annealed. The climate in the locality is mild, with a mean annual temperature of $8.5^{\circ} \mathrm{C}$ and mean annual precipitation of $525 \mathrm{~mm}$ (Hušták 2009). A surface corrosion layer of the sword has been preserved and was stored in the laboratory at room temperature $\left(20-25^{\circ} \mathrm{C}\right)$ and humidity of approximately $30-40 \%$ for one year before the measurement.

For measurement of iron or steel, we could use any material made in Europe before the late $14^{\text {th }}$ century (Read 1934, White 1940, Temple 1989, Degarmo et al. 2003). In this period, iron was not smelted but processed as "weld iron" by hammering the remains of the ore and wood coal from the sponge iron that had been pre-processed by direct reduction of the ore far below the iron ore melting point. The internal structure of the objects was examined by diffraction analysis using photoregistration in the Bragg - 
Brentano semifocusing arrangement (cobalt anode; camera diameter, $114.6 \mathrm{~mm}$; focusing angle, $30^{\circ}$ ), and a large area position-sensitive gas-filled detector (GADDS from Bruker AXS) that provides very good lateral resolution of the registered diffraction patterns.

\section{Results and Discussion}

\subsection{Proof of Forging}

The hardness measured in bronze swords differed between the outside of the blade and the inside: blade, 140-150 Hv; inside (center of the sword), 125-135 Hv (for the sword from Albrechtice nad Vltavou). The hardness of the recently forged replica of the ancient sword was 185-192 Hv inside and 260-268 Hv on the surface of an edge. This difference is proof of forging. Forging as a method of manufacturing bronze weapons is well documented by many measurements in the literature (Shalev 2004).

\subsection{Aging of Bronze Structure}

It was discovered during the measurements that the diffraction coherent areas (mosaic blocks) of the ancient bronze sword (800-450 BC) were larger than $10 \mu \mathrm{m}$, and some were as large as $100 \mu \mathrm{m}$. In Fig. 1(b), there are identifiable diffraction lines formed by solitary reflections (diffraction spots) from large crystallites.

The structure of the bronze sword $(800-450 \mathrm{BC})$ is much more coarse-grained than the structure of the recent replica hardened by forging techniques. In the recent replica, the diffraction lines are fully continuous, as illustrated in Fig. 1(a).

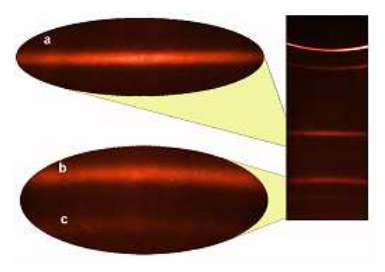

(a)

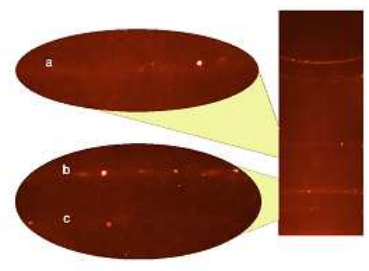

(b)
Figure 1. X-ray diffraction patterns of the bronze samples; detail (ellipse) pictures show the azimuthal (lateral) diffraction profile ( $\underline{a} 220 ; \underline{b} 311 ; \underline{c}$ 22 2) of the copper-rich terminal solid solution (Cu- $\alpha$ ). (a) $X$-ray diffraction patterns of a recent hammered sample of bronze. (b) X-ray diffraction patterns of a sword from the Hallstatt period (ca. 2800-2450 $B P)$. The measurement was conducted on an edge of the blade (ca. $3 \mathrm{~mm}$ from the edge).

As demonstrated through X-ray analysis, the bronze structure coarsened by recrystallization (spontaneous restructuring) during the time (ca. 2700-2800 years) after its production. This process is driven by interface energy which is proportional to the area of the interface between crystallites (grains). A larger number of grains results in their interface having a larger area and thus larger interface energy. At the same time, the coarsening of grains (the growth of their size $d$ ) diminishes the number of grain boundaries, which act as obstacles to the motion of dislocations and the cause of the material's resistance to deformation. In this way, recrystallization reduces the strength of the material, which is quantitatively expressed by the Hall-Petch equation:

$$
\sigma_{y}=\sigma_{i}+\frac{k_{y}}{\sqrt{d}}
$$

in which the yield strength $\sigma_{y}$ is inversely proportional to the square-root of the grain size $d ; \sigma_{i}$ is the so-called Peierls-Nabarro stress necessary for motion of adrift dislocations inside the crystal, and $k_{y}$ is the parameter expressing the strength of the anchoring of dislocations on the boundary of grains. Aging of the bronze causes coarsening of its grains and diminishing of its strength (hardness).

\subsection{Aging of Iron and Steel}

Diffraction patterns of iron objects from the Roman period (50 $\mathrm{BC}-350 / 380 \mathrm{AD})$ and from the Late Medieval Age (1300-1500 AD), which are shown in Figs. 2(a) and 2(b), prove that all these objects are coarse-grained. Coherent areas (mosaic blocks) are larger than $10 \mu \mathrm{m}$, which is observed from the azimuthal profile of the diffraction line (110) of ferrite. The line disintegrates into solitary diffraction spots, which are reflections of the primary X-ray beam on individual crystallites (mosaic blocks).

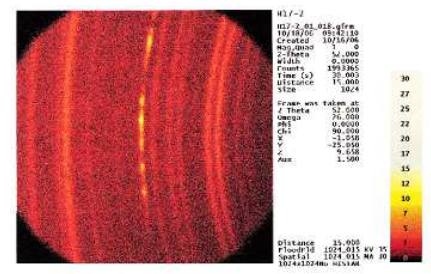

(a)

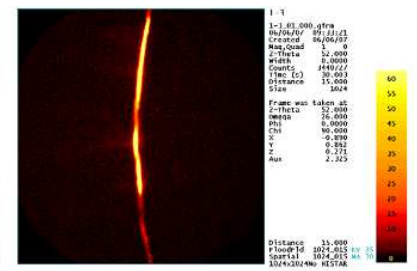

(b)
Figure 2. X-ray diffraction patterns of iron; the images show the azimuthal (lateral) diffraction profiles of the iron solid solution Fe- $\alpha$. (a) X-ray diffraction patterns of a Roman knife (Mušov-Burgstall, 2nd century AD, Czech Republic). (b) X-ray diffraction patterns of an iron axe (Kladruby approximately 1420 AD, Czech Republic)

When the mosaic blocs are smaller, more of them can be included in the irradiated (and diffracting) region, and the number of diffraction spots is thus higher. These spots will start overlapping with each other and form a continuous line, which can be observed in the diffraction pattern of a "standard" that represents contemporary steel - Fig. 3(b). The grains of the investigated objects were much larger than those of contemporary steel samples. In Fig. 3(c), a coarser grain structure is observed in the La Tène sword, the recrystallization of which due to elevated temperature can be safely excluded. 


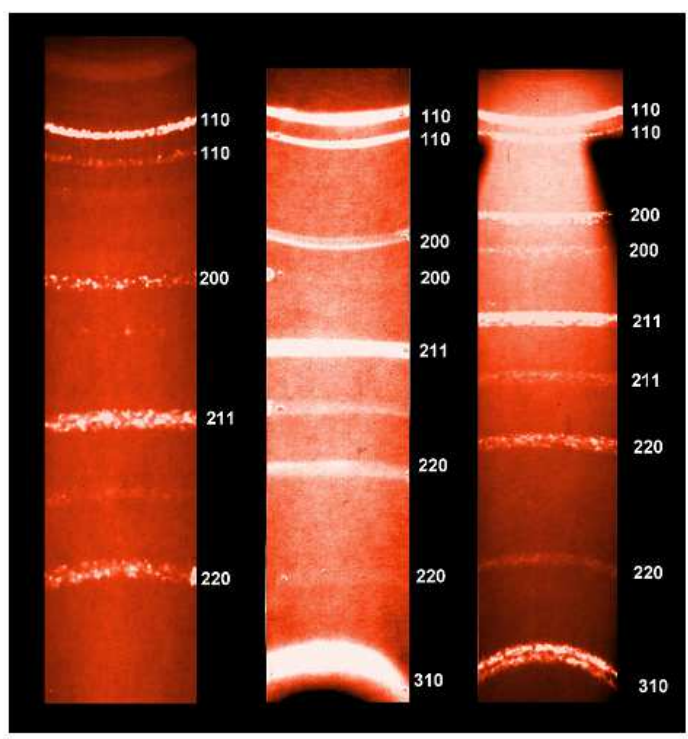

(a)

(b)

(c)

Figure 3. X-ray diffraction patterns of iron; the images show the azimuthal (lateral) diffraction profiles of the iron solid solution $\mathrm{Fe}-\alpha$. (a) Control: $X$-ray diffraction patterns of recent annealed sheet metal.. (b) Control: $X$-ray diffraction patterns of a recent hammered sample of iron. (c) X-ray diffraction patterns of the La Tène culture sword (2200 - 2400 BP).

The object was situated underground for the entire time before X-ray diffraction analysis; yet, the metal shows a coarse-grained structure.

It is highly improbable that all the examined objects were annealed, like the control metal plate in Fig. 3(a), or burned. The tested sword was certainly hammered (Read 1934, White 1940, Temple 1989, Degarmo et al. 2003) and most likely not annealed or secondary-burned.

\subsection{History of Manufactured iron}

Before the $15^{\text {th }}$ century, only sponge iron was manufactured in Europe, by direct reduction of iron ore well below the melting point of iron. Crystals of sponge iron formed in the solid state at that time were much smaller than crystals of iron growing during melt solidification, which is in fact the only way iron is produced at present. Moreover, the intense hammering of sponge iron (which is necessary to remove residual charcoal and unreacted ore) crushed the iron crystals into much smaller pieces (crystallites and mosaic blocks) than the present-day technology of forming (rolling, forging, drawing or extrusion) of the cast iron (steel). However, our analyses proved quite clearly that all archaeological finds (both Roman and medieval) we studied have a coarse-grained structure that must have been developed by recrystallization over many centuries after their manufacture.

\subsection{Low-Temperature Relaxation}

The recrystallization of metallic materials at ambient temperature is closely related to so-called low-temperature relaxation or low-temperature creep. Its principle is a process known as Ostwald's ripening in physical chemistry. Materials age due to low-temperature relaxation. Their structure changes; as a result, their properties also change, particularly their hardness. The structure and properties of archaeological finds at their present state may be rather different from their structure (grain size) and properties (hardness) at the time of manufacture.

Sometimes, the importance of low-temperature relaxation is underestimated in comparison with high-temperature relaxation, which applies in technological processes and is well documented as much more rapid than relaxation at ambient temperature. According to the Arrhenius law,

$$
v=c \cdot e^{-\frac{E}{k T}}
$$

the relaxation rate $v$ exponentially grows with temperature $T$ (where $E=$ activation energy of relaxation, $k=$ Boltzmann constant and $c$ is a proportionality coefficient that does not depend on temperature). According to this law, the relaxation rate $v_{l}$ at ambient temperature $T_{l}$, expressed in terms of the rate $v_{h}$ of the high-temperature relaxation at temperature $T_{h}$,

$$
v_{l}=v_{h} \cdot e^{-\frac{E}{k}\left(\frac{1}{T_{l}}-\frac{1}{T_{h}}\right)}
$$

is not sufficient to significantly reduce the hardness of old archaeological finds, even during the thousands of years that may elapse from their manufacturing. However, such reasoning is not correct. When cooling from high to ambient temperature, the mechanism of relaxation changes. Some low-energy mechanisms are blocked at elevated temperatures $T_{h}$ but released at ambient temperatures $T_{l}$; the activation energy $E_{l}$ of such mechanisms is much lower than the activation energy $E_{h}$ of relaxation processes at elevated temperatures. At ambient temperature, vacancies agglomerate and form chains along which the diffusion of atoms, mediating relaxation processes, proceeds at a rate several orders of magnitude faster than that through the matrix. Therefore, instead of equation (1), another equation holds true, namely

$$
v_{l}=v_{h} \cdot e^{-\frac{1}{k}\left(\frac{E_{l}}{T_{l}}-\frac{E_{h}}{T_{h}}\right)}
$$

Assuming $E_{l}<E_{h}$, the rate of the ambient-temperature relaxation, calculated from equation (2), is much greater than that computed from equation (1). Thus, for $E_{h}=1.5 \mathrm{eV}$ and $E_{l}=1.3 \mathrm{eV}$ (where $T_{h}=$ melting point and $T_{l}=$ room temperature), the value of $v_{l} / v_{h}$ increases approximately 830 times (in the case of iron), which confirms that the strength of a two thousand year-old bronze sword might be considerably reduced by recrystallization.

Because bronze melts at a lower temperature $\left(900^{\circ} \mathrm{C}\right)$ than iron $\left(1540^{\circ} \mathrm{C}\right)$, recrystallization of bronze occurs faster than recrystallization of iron under the same atmospheric 
conditions (with the speed of recrystallization being given by the so-called homologous temperature, which is the ratio of the actual temperature and the melting temperature). Thus, bronze changes its structure and softens more rapidly than do iron and steel.

\section{Conclusion}

Our results show that metals change their characteristics in the course of time due to spontaneous recrystallization at ambient temperature. The change is distinctive mainly in materials produced by hammering, which results in the compaction of material. Contemporary structure and characteristics, specifically hardness, of the hammered metal artifacts may be very different from their structure and properties when freshly manufactured (Fig. 4).

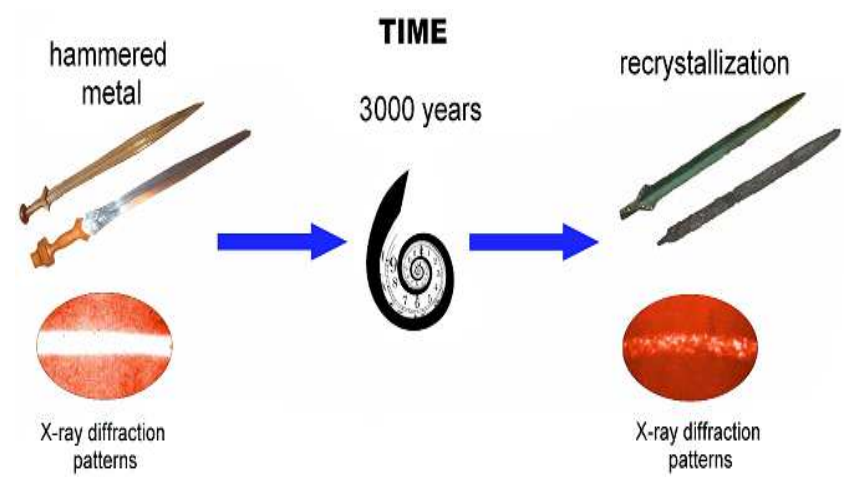

Figure 4. Graphical recapitulation of results

The results obtained are remarkably important from two perspectives: 1) they reflect changes in the characteristics of metal objects and equipment (functional degradation) that are being used at present, and 2) they are relevant to the investigation of material changes in metal archaeological artifacts. The significance of low-temperature relaxation is sometimes underestimated in comparison to high-temperature relaxation. However, spontaneous recrystallization may occur at ambient temperature much more quickly than usually assumed. Significant deviations from the original state appear sometimes after a rather short time interval. Such changes in metal characteristics over time are often not taken into account, which may be fateful when estimating the residual life of engineering components. Our results represent a significant contribution to the recent development of techniques for monitoring material degradation.

\section{Note}

Bronze swords: the Albrechtice nad Vltavou fragment, younger Bronze Age, inventory number J.II.64, Museum of South Bohemia, Dukelská 242/1, České Budějovice, 37001 Czech Republic; and the entire sword, Hallstatt period, Jarošovice, inventory number 2166, Town Museum, Náměstí Míru 1, Týn nad Vltavou, 37501 Czech Rep.

\section{Acknowledgements}

The authors wish to thank Věra Pavelková and Ladislav Šmejda for helpful suggestions. This research was supported by the Archaeological strategies grant CZ.1.07/2.3.00/20.0036

\section{References}

[1] Angelini E. De Benedetti B. \& Rosalbino F. 2004 Corrosion Science. Vol. 46, No 6, pp 1351-1367

[2] Artioli G. Dugnani M. Hansen T. Lutterotti L. Pedrotti A. \& Sperl G. 2003 in: "The Copper Age mummy. 2. New finds on the Iceman". edited by Fleckinger A. Museo Archeologico dell'Alto Adige Vol. 3 Folio Verlag Bolzano pp 9-22

[3] Artioli G. \& Dugnani M. 2004 Periodicko Mineralogia Vol.73, pp 5-16

[4] Bernier P. 2003 Journal of Physics and Chemistry of Solids Vol. 64, No 4, 64 pp 571-581

[5] Bourdoiseau J.A. Jeannin M. Sabot R. Remazeilles C. \& Refait P. 2008 Corrosion Science Vol. 50, No. 11, pp $3247-3255$

[6] Buchwald V. F. 2005 in: Iron and steel in ancient times. Kgl. Danske Videnskabernes Selskab pp 45-46. Printed in Denmark by Special-Trykkeriet Viborg a-s ISBN 87-7304-308-7

[7] Castellero A. Moserb B. Uhlenhauta D.I. Dalla Torrea F.H. \& Löfflera J.F. 2008 Acta Materialia. Vol. 56, No. 15, pp $3777-3785$

[8] Degarmo E. P. Black J T. \& Kohser R. A. 2003 Materials and Processes in Manufacturing 9th ed. Wiley ISBN 0-471-65653-4

[9] Duclaux L. Salvetat J.P. Lauginie P. Cacciaguera T. Faugere A.M. Goze-Bac C. Bernier P. 2003 Synthesis and characterization of SWNT-heavy alkali metal intercalation compounds, effect of host SWNTs materials. Journal of Physics and Chemistry of Solids, Vol. 64, No. 4, pp 571-581

[10] Fiala J. \& Kolega M. 2005 Particle and particle system characterization Vol. 22 pp $397-400$

[11] Fiala J. \& Kocich R. 2006. In: 36 conference DEFECTOSCOPY 2006. Rekrystalisace při únavě a creepu (Recrystallization at fatigue and creep).

[12] Fiala J. Schindler I. Foret R. \& Němeček S. 2002 Strojnický časopis Vol. 53, pp 1-23

[13] Fiala J. \& Snyder R.L. 1999 in: "Defect and microstructure analysis by diffraction". edited by Snyder R.L. Fiala J. \& Bunge H.J. pp 1-15 Oxford University Press New York

[14] Grömer K. \& Mödlinger M. 2005 Archäologie Österreichs Vol. 16, No.2, pp 51-55

[15] Guoa Z. Shaa W. \& Vaumousseb D. 2003 Acta Materialia. Vol. 51, No.1, pp 101-116

[16] Hušták P. 2009 Polyfunkční areál "Jiviny /Karlovarská“ Praha 6 - Ruzyně Karlovarská ul. Nálezová zpráva archiv nálezových zpráv ARÚP Praha. (Archaeology 
report)

[17] McConchie M. 2004 in: Iron technology and ironmaking communities of the first millennium BC. Peeters Publishers. ISBN 90-429-1389-4. pp 56. Printed in Belgium 56

[18] Mohan R. \& Marschall C. 1998. Acta Materialia. Vol. 46, No.6, pp 1933-1948

[19] Mödlinger M. 2005 Archäologie Österreichs. Vol. 15, No.2, pp 26-29

[20] Read T. T. 1934 Geographical Review xxiv 544-554; 'Largest and oldest iron-castings' Iron Age cxxxvII 1936 pp 18-20

[21] Shalev S. 2004 Prähistorische Bronzefunde Abteilung IV 13. Band. Printed in Germany ISBN 3-515-08198-4 72

[22] Sun Y. Li X.Y. \& Bell T. 1999 Journal of Materials Science Vol. 34, No.19, pp 1573-4803

[23] Temple R. 1989 Discovery and Invention pp 42-44. New York: Simon \& Schuster

[24] White L.. Jr. 1940 in: Speculum Vol. 15 No. 2 pp 141-159 Published by: Medieval Academy of America 